\title{
Estudo comparativo exploratório dos planos nacionais de educação no Brasil e na Colômbia ${ }^{1}$
}

\author{
Exploratory comparative study on national plans of education in Brazil and \\ Colombia \\ Estudio comparativo exploratorio de los planes nacionales de educación en \\ Brasil y en Colombia
}

DIANA MARCELA CUERVO-ESCOBAR

CINTIA DA COSTA

ALICIA MARIA CATALANO DE BONAMINO

\begin{abstract}
Resumo: Esta pesquisa procurou compreender o planejamento educacional público, a partir da comparação dos documentos dos Planos Nacionais de Educação do Brasil e da Colômbia. Por meio de uma Análise de Conteúdo, focada no eixo qualitativo, empreendemos um estudo exploratório dos planos centrados nos temas-marco e nas metas, bem como na estrutura dos documentos. As principais conclusões apontam que os planos têm origem político-social similar, compartilham o vínculo com uma agenda mundial para o planejamento educativo e apresentam uma série de tensões entre os fins da educação e os meios para atingi-los.
\end{abstract}

Palavras-chave: Planejamento educacional; Plano Nacional de Educação; análise de conteúdo; política pública.

\begin{abstract}
This investigation intended to comprehend public educational planning through the comparison of documents on National Educational Planning from Brazil and Colombia. Carrying out a qualitative Content Analysis and focused on the general topics, goals and the formal traits of the documents, an exploratory study was done. The main conclusions point that the documents have a similar socio-political origin, they share their link with a worldwide agenda for the educational planning and there are tensions between educational objectives and the means for achieving them.
\end{abstract}

Keywords: Educational planning; National Education Plan; content analysis; public policies.

Resumen: Esta investigación buscó comprender la planeación educativa pública, a partir de la comparación de los documentos de los Planes Nacionales de Educación de Brasil y de Colombia. Por medio de un Análisis de Contenido, enfocado en el eje cualitativo, emprendimos un estudio exploratorio de los planes, centrado en los temas-marco y las metas, así como en la estructura de los documentos. Las conclusiones principales demuestran que los planes tienen un origen político-social similar, comparten el vínculo con una agenda mundial para

1 O presente trabalho foi realizado com apoio do Programa Estudantes-Convênio de Pós-graduação - PEC-PG, da CAPES/CNPq - Brasil. 
la planeación educativa y presentan una serie de tensiones entre los fines de la educación y los medios para alcanzarlos.

Palabras clave: Planificación educativa, Plan Nacional de Educación, análisis de contenido; política pública.

\section{INTRODUÇÃO}

A análise do planejamento educacional torna-se importante para a compreensão da intenção normativa de práticas políticas e pedagógicas no cotidiano do sistema educativo. Os planos nacionais de educação são a máxima expressão do planejamento educacional de cada país, pois para eles confluem os interesses de diversos setores governamentais e da sociedade civil que participam na sua elaboração. De acordo com Mendes (2000), o planejamento educacional envolve uma ruptura com o espontaneísmo e, em contextos democráticos, um exercício deliberativo, no qual o estado estrutura a discussão em torno das prioridades da educação, registrando os consensos num documento a ser levado em conta nos planos das diferentes esferas governamentais.

Neste texto, busca-se contribuir para a compreensão desse planejamento público do dever ser da educação, por meio da comparação dos planos nacionais de educação de dois países latino-americanos, Brasil e Colômbia, os quais, apesar de diferenças significativas de natureza política e cultural, enfrentam desigualdades e desafios educacionais semelhantes.

Interessa-nos saber como se deu a elaboração dos planos nesses dois países e o que podemos depreender de sua comparação, numa análise de natureza exploratória dos documentos, suas metas e estratégias.

Além desta introdução, o texto está organizado em seis seções. A segunda seção apresenta sucintamente a metodologia usada no estudo e a terceira uma síntese da origem dos planos nacionais de educação no Brasil e na Colômbia. A seguir, são descritos os processos de elaboração dos documentos vigentes nesses dois países, a saber: o Plano Nacional de Educação (PNE 2014-2024) e o Plan Nacional Decenal de Educación (PNDE 2006-2016), aos quais nos referiremos genericamente como PNEs. A quinta seção apresenta a análise das principais semelhanças e diferenças formais e de conteúdo encontradas nos documentos analisados. Finalmente, a seção seis é dedicada às conclusões.

\section{METODOLOGIA}

A metodologia escolhida para este estudo foi a Análise de Conteúdo (AC). Segundo Bauer (2003), a AC “é uma técnica para produzir inferências de 
um texto focal para seu contexto social de maneira objetivada" (BAUER, 2003, p.191). A AC permite fazer análise textual a partir de um mecanismo híbrido (qualitativo e quantitativo), que torna possível a simplificação da complexidade de uma coleção de textos, a construção de índices, a reconstrução de representações semânticas, sintáticas, retóricas e a elaboração de mapas de conhecimento. Com essas representações, o pesquisador pode fazer conjeturas e inferências sobre "valores, atitudes, estereótipos, símbolos e cosmovisões de um texto sobre o qual pouco se sabe" (BAUER, 2003, p.193). Embora seja levado em conta o contexto, o que prima na AC é o texto (BAUER, 2003).

Para o autor, as vantagens do uso de AC é que esta é sistemática e pública, faz uso principalmente de dados brutos que ocorrem naturalmente, pode lidar com grandes quantidades de dados, presta-se a dados históricos e oferece um conjunto de procedimentos maduros e bem documentados. Em relação às fraquezas, o autor assinala que a AC é comumente criticada por introduzir inexatidões de interpretação, ao separar as unidades de análise, pois "citações fora do contexto podem ser enganadoras" (BAUER, 2013, p.213). Também aponta que, ao focar-se nas freqüências, a AC deixa de lado as ausências e o que não é usual e, finalmente, que esta técnica "apresenta primariamente dados a nível coletivo, caracterizando, desse modo, algo coletivo através de dados remanescentes de comunicação e expressão" (BAUER, 2003, p.213).

Pela natureza exploratória e comparativa do estudo proposto, assim como pela ênfase nas dimensões formais e de conteúdo mais gerais dos documentos, optamos por adotar o eixo qualitativo da AC. O eixo quantitativo (contagem de palavras, frequências etc) é útil para analisar os documentos na sua totalidade, mas desnecessário para a análise de vários enunciados.

\section{ORIGENS DOS PLANOS NACIONAIS DE EDUCAÇÃO}

No Brasil e na Colômbia, os PNEs respondem a demandas contextuais diferenciadas que fazem parte de uma história de debates, de normatividades e de lutas sociais pela inclusão e o cumprimento dos direitos educacionais.

\section{PLANEJAMENTO EDUCACIONAL NA COLÔMBIA}

$\mathrm{Na}$ Colômbia, os planos nacionais de educação enquanto documentos indicativos específicos surgem na década de 1990, embora seja possível identificar uma primeira experiência na década de 1950 e outras iniciativas presentes nos planos governamentais de desenvolvimento. 
Em 1957 foi elaborado o primeiro plano quinquenal de educação pelo especialista em organização e supervisão escolar José Blat Gimeno, comissionado pela UNESCO para avaliar o estado da educação colombiana e formular um plano que atendesse às prioridades educacionais do país. Segundo Herrera e Infante (2004), os planos posteriores foram formulados no marco dos planos de desenvolvimento social e econômico governamental, prescritos pela reforma constitucional de 1968, fazendo com que cada plano elaborado a partir de 1970 correspondesse às prioridades identificadas pelo candidato presidencial eleito e tivesse duração de, no máximo, quatro anos. ${ }^{2}$

Com a reforma constitucional de 1991, Colômbia declara-se um estado social de direito e uma República Unitária descentralizada. Para a educação, a reforma tem duas implicações importantes: a formalização da descentralização administrativa da educação e a promulgação da Ley 115 de 8 de Febrero de $1994^{3}$ (lei geral de educação). Embora a lei tenha sido criticada pelo fato de não incluir a educação superior na estrutura do sistema educacional e por omitir a regulação do caráter público da educação, que já tinha sido consagrado na Constituição de 1991, foram vários os ganhos dela decorrentes. Entre eles a atribuição ao Ministerio de Educación Nacional (MEN) da elaboração de planos decenais de educação e a criação de mecanismos de participação cidadã na formulação de políticas educacionais. (CAJIAO, 2004) Isso está expresso no artigo 72 da Lei 115/1994 (COLÔMBIA, 1994) da seguinte forma:

Plan Nacional de Desarrollo Educativo. O Ministerio de Educación Nacional, em
coordenação com as entidades territoriais, preparará pelo menos a cada dez (10)
anos El Plan Nacional de Desarrollo Educativo, que incluirá as ações correspondentes
para dar cumprimento aos mandados constitucionais e legais sobre a prestação
do serviço educativo. Este plano terá caráter indicativo, será avaliado, revisado
permanentemente e considerado nos planos nacionais e territoriais de
desenvolvimento (COLÔMBIA, 1994 - tradução nossa) ${ }^{4}$.

As características gerais do plano colombiano podem ser assim resumidas: é decenal, deve ser incluído no planejamento governamental (local, regional e nacional) e é indicativo. Essa última característica é de especial importância para a finalidade deste estudo, seja em termos jurídicos, porque significa que o cumprimento do plano não é obrigatório, seja porque evidencia a primeira

\footnotetext{
2 Até hoje, não existe na Colômbia um estudo que analise a história dos planos nacionais de educação nem seus resultados e impactos.

3 Esta lei é comumente conhecida na Colômbia como Ley General de Educación.

4 Extraído da seção "Normatividad" da página do PNDE: http://www.plandecenal.edu.co/ html/1726/w3-propertyvalue-44262.html. Consultado o dia 24 de novembro de 2014.
}

174 - RBPAE - v. 32, n. 1, p. 171 - 192 jan./abr. 2016 
diferença formal com o plano brasileiro, cuja especificidade é ter força de lei. Retomaremos esse tema na próxima seção.

Dois anos após a aprovação da lei geral de educação foi elaborado novo plano educacional nacional na Colômbia, o "PNDE 1996-2005. La educación um compromiso de todos", cujo lema respondeu em parte ao fato de ter sido a primeira vez que, além do MEN e suas secretarias, setores da sociedade civil sem envolvimento direto com a prestação do serviço educativo, como ONGs e meios de comunicação, participaram de sua elaboração. (RODRÍGUEZ ${ }^{5}, 2002$ )

Não obstante essa participação ampliada, o plano foi ignorado pelos governos que sucederam ao governo de Samper ${ }^{6}$ e muitas de suas proposições se tornaram letra morta. De fato, embora os governos de Samper, de Pastrana ${ }^{7}$ e o primeiro de Uribe $^{8}$ tenham acontecido no período de vigência do plano, nenhum deles incluiu suas disposições nos respectivos planos de desenvolvimento nem a sociedade civil exerceu pressão alguma para seu cumprimento.

\section{PLANEJAMENTO EDUCACIONAL NO BRASIL}

No Brasil, o PNE 2001-2011 foi o primeiro plano aprovado com força de lei, embora se registrem inúmeras tentativas anteriores de organização da educação por meio de planos nacionais, como é ilustrado pelo fato de a Constituição de 1934, no art. 150, ter tornado obrigatória a formulação de um Plano Nacional de Educação, que chegou a ser elaborado pelo Conselho Nacional de Educação em 1937. O entendimento era de que o plano deveria obedecer a uma racionalidade técnica que garantisse a autonomia dos educadores e do governo. Esse plano foi abandonado com o advento do Estado Novo9. Em 1962, um novo plano estabeleceu critérios para o uso de recursos públicos e formulou um conjunto de metas a serem alcançadas em oito anos. Mais tarde, em 1993, foi elaborado um novo plano que contemplava o Ensino Fundamental e não chegou a ser implantado.

O PNE com força de lei cobriu o decênio 2001-2011, tendo sido preconizado pela Constituição de 1988, no art. 214, e pela LDB 9394/96, art. 87.

\footnotetext{
5 Abel Rodríguez, além de ser o autor de uma das referências citadas neste texto, foi o Gerente do primeiro plano nacional da Colômbia, e Vice-ministro e Ministro encarregado de Educação, em meados da década dos noventa.

6 Ernesto Samper Pizano foi o presidente da Colômbia no período de 1994-1998.

$7 \quad$ Andrés Pastrana Arango foi o presidente de 1998 a 2002.

8 Álvaro Uribe Vélez foi o presidente em dois períodos: 2002 - 2006 e 2006 - 2010.

9 Estado Novo é conhecido como o período presidencial do Governo de Getúlio Vargas, compreendido entre 1937 e 1945.
} 
Esse PNE se configurou mais como uma carta de intenções do que propriamente como um planejamento da educação nacional, já que propôs metas, mas não definiu com clareza as estratégias para seu alcance, principalmente no caso do orçamento (VALENTE; ROMANO, 2002).

A origem dos planos nos dois países permite identificar aproximações e diferenças. Com efeito, no Brasil, desde a década de 1930, registra-se um direcionamento constitucional voltado para a criação de planos nacionais de educação, enquanto na Colômbia, o tema aparece aproximadamente 35 anos depois e os planos educacionais ficam subordinados ao planejamento do desenvolvimento geral pelo governo. No entanto, nos dois países, foi no âmbito das novas constituições e das leis gerais da educação que se deram a elaboração e implementação de planos nacionais decenais de educação no Brasil (PNE 20012011) e na Colômbia (PNDE 1996-2005). No caso brasileiro, com força de lei, com intenção indicativa; no caso colombiano, os dois planos foram elaborados em processos que contaram com a participação da sociedade civil, embora não tenham chegado a se constituir, na prática e durante sua vigência, em referências fortes para as políticas educacionais.

\section{PROCESSO DE ELABORAÇÃO DOS PLANOS ATUALMENTE VIGENTES}

\section{O PNDE 2006-2016 NA COLÔMBIA}

O "Plan Nacional Decenal de Educación (PNDE) 2006-2016. Pacto social por La educación” da Colômbia é o segundo elaborado no país e levou em conta dois aprendizados decorrentes do primeiro plano: a necessidade de se ampliar a base deliberativa e participativa na fase de formulação, e a importância de reinterpretar o caráter indicativo do plano de modo a torná-lo um documento reitor do planejamento educacional nos diferentes governos, âmbitos e instituições educacionais. (COLÔMBIA, 2014, p.4)

Respondendo à necessidade de ampliação da deliberação e da participação, a construção do plano passou por quatro etapas: 1. Documentação, isto é, um balanço geral do plano anterior; 2. Construção da agenda para o debate público com a participação de figuras públicas e instituições educacionais que definiram os dez temas do documento final; 3. Debate público em mesas de trabalho, foros virtuais e consultas cidadãs e, 4. Elaboração do PNDE 2006-2016 pela Asamblea Nacional por La Educación, constituída por representantes de diferentes setores que participaram da etapa anterior. O documento final foi redigido por uma comissão designada pela assembleia que reuniu os relatórios dos grupos de trabalho. As

176 - RBPAE - v. 32, n. 1, p. 171 - 192 jan./abr. 2016 
deliberações e a redação do documento pautaram-se por uma "regra primordial", segundo a qual,

Os consensos e unanimidades não devem ser impostos, através de nenhum mecanismo de eliminação, votação ou anulação de pontos de vista, e se adotarão, em todos os casos, os dissensos, mesmo que provenham de uma só pessoa, como aportes válidos que deverão ficar registrados na relatoria da deliberação. (COLÔMBIA, PNDE, p. 9 - tradução nossa).

O caráter indicativo do documento derivou do mal-estar do campo educacional provocado pelos governos, que chegaram a alinhar suas políticas educacionais com as disposições do plano de maneira explícita e sistemática. Em razão disso, a estrutura do plano foi reformulada, de forma que o segundo plano estabeleceu horizontes comuns durante ou para a década coberta pela vigência e definiu objetivos, metas e ações a serem incorporados nos planejamentos regionais, municipais e institucionais, conforme as necessidades específicas de cada contexto.

O atual PNDE colombiano se configura como um conjunto de processos deliberativos, acordos e ações para direcionar a educação no decênio. Segundo o documento, o PNDE 2006-2016 é

Um pacto social pela educação que contém os lineamentos para o desenvolvimento educacional do país nesse período de tempo. Constiitui-se num documento de referência obrigatória para a formulação dos planos nacionais e territoriais de desenvolvimento, segundo mandato da Ley General de Educación, e deve ser levado em conta pelas instituições educativas do país nos seus processos de planejamento, de acordo com o alcance previsto e estipulado pelo Plano. (COLÔMBIA, PNDE, p. 3 - tradução e grifo nossos)

Como pacto social pelo direito à educação, o principal objetivo do plano é que tanto as instituições como a sociedade civil (sobretudo aqueles setores que não participaram da elaboração do primeiro plano) se comprometam com a identificação dos temas e ações prioritários da educação na Colômbia e participem da tomada de decisões que delimitarão o planejamento educacional do decênio.

Formalmente, o documento da Colômbia responde a um modelo de comunicação pública organizacional ${ }^{10} \mathrm{e}$ é um compêndio de consensos e dissensos de 138 páginas divididas em quatro capítulos, a saber: 1) Desafio da educação na Colômbia, 2) Garantias para o pleno cumprimento do direito à educação na Colômbia, 3) Agentes educacionais e 4) Mecanismos de supervisão, avaliação e

10 O que supõe que o plano é visto como uma organização e, portanto, há um gerente; os professores são nomeados como talento bumano e, ao se falar de resultados, usam-se recorrentemente termos como standards e guias técnicas. 
participação do PNDE (tradução nossa). Dentro dos capítulos estão organizados os temas-marco do documento contendo macro-objetivos, objetivos, macrometas, metas e ações e, no último capítulo, estão definidos os entes encarregados da supervisão e da avaliação do plano.

\section{O PNE 2014-2024 NO BRASIL}

No Brasil, o processo de elaboração do Plano Nacional da Educação (2014-2024) teve dois grandes momentos. O primeiro abrange o período de discussão pela sociedade civil e o segundo, o momento em que o documento ingressa no Congresso Nacional, iniciando a discussão na comunidade política.

Para o primeiro momento de discussão e elaboração do plano contribuíram o Conselho Nacional da Educação ${ }^{11}$ (CNE) e a Conferência Nacional de Educação ${ }^{12}$ (CONAE) 2010, que levaram em conta o PNE 20012010 e o Plano de Desenvolvimento da Educação ${ }^{13}$ (PDE). As contribuições do CNE partiram das avaliações do PNE realizadas pela Comissão de Educação e Cultura da Câmara dos Deputados, pelo MEC e contou com outros estudos, dentre eles o que foi conduzido por Cury (2009). Como resultado dessas ações, o CNE formulou, em 2009, o documento intitulado de "Indicações para subsidiar a construção do Plano Nacional de Educação 2011-2020”, onde foram estabelecidos os dez desafios da Educação Nacional. ${ }^{14}$

A contribuição da CONAE 2010 foi o Documento-Referência, cuja elaboração contou com a participação de secretarias do MEC, das Comissões de Educação e Cultura da Câmara e do Senado, do CNE, de entidades dirigentes, de conselhos de educação, de instituições de nível superior e seus estudantes, entre outros. Os documentos foram discutidos em plenárias de Eixo e na Plenária Final da conferência, que aprovou as emendas consubstanciando o documento final.

Já o segundo momento se inicia com a entrada do Projeto de Lei (PL 8035/2010) na Câmara de Deputados do Congresso Nacional, em março de 2011, na qual foi criada uma comissão especial para elaboração do parecer do projeto, que acabou sendo prorrogada sucessivas vezes. É importante registrar que muitas emendas partiram de entidades da sociedade civil ligadas à educação, mostrando

11 O Conselho Nacional de Educação é um órgão colegiado integrante da estrutura do Ministério da Educação do Brasil, com a função de formular e avaliar a política nacional de educação.

12 A Conferência Nacional de Educação (CONAE) é um espaço democrático aberto pelo Poder Público e articulado com a sociedade para participação do no desenvolvimento da Educação Nacional.

13 O Plano de Desenvolvimento da Educação (PDE) é uma política do governo federal lançada no ano de 2007, que tem como objetivo a melhoria da Educação Básica através de 30 programas educacionais.

14 Portaria CNE/CP n ${ }^{\circ} 10$, de 06 de agosto de 2009.

178 - RBPAE - v. 32, n. 1, p. 171 - 192 jan./abr. 2016 
que o debate não esteve circunscrito ao âmbito parlamentar. Finalmente, o plano foi aprovado em 2014, sob a Lei número 13005/2014.

O PNE tem como principal função a articulação do regime de colaboração entre os entes federados com vistas à universalização da oferta da etapa escolar obrigatória (de 4 a 17 anos), à elevação do nível de escolaridade e da taxa de alfabetização da população, à melhoria da qualidade da educação básica e superior, à ampliação do acesso ao ensino técnico e superior, à valorização dos profissionais da educação, à redução das desigualdades sociais, à democratização da gestão e à ampliação dos investimentos em educação.

Trata-se de um planejamento de médio prazo que orienta as ações na área educacional e estabelece responsabilidades que deverão ser compartilhadas entre a União, os estados, o Distrito Federal e os municípios. Possui duas características importantes: tem força de Lei e é decenal, o que significa que deve ultrapassar diferentes gestões de governo, superando, dessa forma, a descontinuidade das políticas públicas a cada mudança de condução político-partidária. Formalmente, o documento está dividido em duas partes: a lei, contendo as diretrizes, e seu anexo, contendo as metas e as estratégias.

\section{SEMELHANÇAS E DIFERENÇAS ENTRE OS DOIS PLANOS}

A análise dos documentos dos dois países poderia guiar-nos por diferentes rotas de interpretação, que incluem desde uma visão mais instrumental e formal até outra que tentasse explicitar os valores subjacentes ou a ideologia implícita. A primeira abordagem pouco diria sobre como os planos se inscrevem num sistema social que busca atingir metas educacionais. A segunda exigiria uma pesquisa mais ampla e uma metodologia que escapa ao nosso propósito de oferecer um estudo comparativo exploratório. O que esta seção oferece ao leitor é uma comparação inicial dos documentos em dois níveis: o formal e o de conteúdo. No segundo, limitar-nos-emos à análise daqueles conteúdos mais gerais. Dada a disparidade na quantidade de propósitos e agentes envolvidos nos respectivos planos, pretendemos focar nossa atenção naqueles aspectos que podem ser comparados sem que se corra o risco de cometer erros argumentativos.

\section{INDICAÇÃO VS. PRESCRIÇÃO}

Para começar, retomaremos uma diferença que já tinha sido mencionada: o PNE colombiano é um documento indicativo enquanto o brasileiro é uma lei, o que significa que, enquanto o documento brasileiro é de cumprimento obrigatório, o colombiano é obrigatório apenas enquanto referência. 
No documento colombiano afirma-se que o mesmo "[deve cumprir] cabalmente a função de marco contextual de obrigatória referência" (COLÔMBIA, PNDE, p. 10 - tradução nossa). Assim, mesmo sem força de lei, a introdução do PNE colombiano destaca como obrigatória para os entes envolvidos no planejamento educacional a leitura e consulta do documento para que suas diretrizes se façam presentes nos planos institucionais educacionais e nos planos de desenvolvimento governamentais.

Por sua vez, o PNE brasileiro tem formato e força legais. A natureza federativa do Brasil, que pressupõe a descentralização e a autonomia dos entes federados, torna necessário que todo instrumento normativo seja também um instrumento jurídico a fim de que seja observado e garantido pela União, pelos estados e municípios.

Não estamos aqui comparando a implantação de fato dos planos e não podemos afirmar que a diferença na forma jurídica dos mesmos tenha peso real no cumprimento dos propósitos estabelecidos. No entanto, podemos sinalizar duas questões relevantes em relação a esta diferença. Por um lado, uma lei é um instrumento de pressão com o qual a sociedade civil conta para exigir o respeito de seus direitos, neste caso, do direito à educação. Por outro lado, no caso colombiano uma contradição parece existir entre a preocupação com a intensificação do caráter democrático do planejamento educacional e a falta de respaldo jurídico para sua concretização. Na Colômbia, ao lado do esforço estatal dirigido a assegurar a maior participação possível da sociedade civil na elaboração do plano está o caráter apenas indicativo do mesmo prescrito pela Ley General de Educación de 1994, o que parece implicar uma limitação da representação dos interesses da sociedade civil à letra do plano, deixando o atendimento factual desses interesses na dependência da boa vontade governamental e institucional.

\section{OS DISSENSOS REGISTRADOS NO DOCUMENTO COLOMBIANO ${ }^{15}$}

Outro aspecto importante é que, diferentemente do documento brasileiro, o plano colombiano contém o registro dos dissensos presentes nas discussões das mesas de trabalho. Em um exercício "extremo" de democracia, o documento quis mostrar que não só foi ouvida a voz da maioria mas também de absolutamente todos os que participaram das discussões. Esses dissensos merecem atenção de nossa parte pelo fato de permitir visualizar a disputa pelos usos da presentes em toda sua elaboração, principalmente, no segundo momento de discussão no Congresso Nacional.

180 - RBPAE - v. 32, n. 1, p. 171 - 192 jan./abr. 2016 
língua, a polarização ideológica dos participantes da assembleia que deu origem ao plano e os graus de importância e complexidade dos temas tratados.

Em relação à disputa pelos usos da língua, encontramos frases que questionam a forma de nomear, adjetivar ou definir algum processo, atividade, instituição ou agente próprio ao campo educacional. Por exemplo, em relação ao tema da dotação e da infraestrutura há uma meta que estabelece:

Fornecer, fortalecer e providenciar a manutenção de infraestruturas tecnológicas de qualidade, nas instituições e centros educativos; com a finalidade de contribuir para o desenvolvimento e uso de redes informáticas e conhecimento pedagógico de alta qualidade, em condições de equidade. (COLÔMBIA, PNDE, p. 43 - tradução nossa)

Os dissensos para esta meta são: "Substituir instituições educativas por estabelecimentos educativos", "a palavra instituição educativa inclui todos os tipos de centros educativos.”(COLÔMBIA, PNDE, p. 43 - tradução nossa)À primeira vista, instituição pode ser considerado sinônimo de estabelecimento. Contudo, para o sistema educacional público colombiano as instituições educativas são aquelas que garantem todas as séries escolares obrigatórias até o nono grau, enquanto, os estabelecimentos são a somatória das "instituições" e dos "centros educativos", que se caracterizam por oferecer só algumas dessas séries.

Esta disputa geralmente está associada à polarização ideológica presente no âmbito religioso, político, econômico e cultural. Por exemplo, quando é abordado o tema do investimento e da gestão há um desacordo em relação à porcentagem do PIB que deveria ser destinado à educação:

Em 2016, os recursos - de fontes estatais, privadas e internacionais - destinados ao setor educativo, terão crescido progressivamente até os $7 \%$ do PIB. [...] Dissenso: Para alguns membros da assembleia, o PIB para a educação deveria chegar até o 6\%. (COLÔMBIA, PNDE, p.69 - tradução nossa).

Em diversos trechos do texto é possível identificar, também, essa disputa ideológica, como pode ser visto no exemplo a seguir:

Moldar e implementar um sistema de monitoramento, um sistema de avaliação para a qualidade da educação de forma contínua, permanente, integral, integrada e contextualizada para atores, instituições e processos que responda a resultados académicos e institucionais, com base em parâmetros referenciados em âmbito local, regional, nacional e internacional, e de acordo com o marco jurídico e conceitual estabelecido.

Dissenso: O sistema de avaliação tem foco nos resultados, portanto, não é assumido como um sistema de avaliação do processo. Deve-se especificar quem devem ser avaliado. Deve existir um controle por parte de governadores e prefeitos 
e este aspecto não está presente no objetivo aceito. Deve haver, portanto, tanto um contexto nacional quanto local, e portanto as autoridades locais devem constituirse como observadores de processos acadêmicos. Deve-se ter presente que as competências são inerentes aos sistemas avançados de gestão. (COLÔMBIA, PNDE, p.16 - Tradução nossa)

É importante destacar, no entanto, que alguns dissensos foram sumariamente descritos, especialmente no caso daqueles que apresentavam um número maior de dissensos, o que indicia a complexidade de alguns dos temas tratados e dos interesses envolvidos na elaboração do documento. De fato, excetuando-se o tema da ciência e da tecnologia, os dissensos aparecem em todos os temas-marco que compõem o documento, totalizando quarenta e sete dissensos. Chama a atenção que a distribuição se concentre, em primeiro lugar, no tema da "Formação, desenvolvimento profissional e dignificação dos e das docentes e diretivos docentes" (13 dissensos) e, em segundo lugar, no da "Equidade: aceso, permanência e qualidade" (7).

Essa distribuição coloca temas em destaque nos dissensos que questionam o estatuto docente (debate sobre a modificação do estatuto e seu impacto nas atuais condições docentes), a educação infantil (faixa etária, obrigatoriedade e gratuidade), avaliação (quem deveria ser avaliado, se seriam avaliados os processos ou somente os resultados), a descentralização e a autonomia e o investimento e gestão na educação (beneficiários, orçamentos, o caráter da educação, administração dos recursos).

\section{OS TEMAS-MARCO}

As metas dos dois planos estão contextualizadas em dez grandes temasmarco que representam os desafios da educação para um decênio e são o ponto de partida para a definição das metas e ações. No caso brasileiro, os temasmarco são denominados de "diretrizes". Embora a Constituição Federal de 1988 estabelecesse apenas cinco diretrizes para o $\mathrm{PNE}^{16}$, o atual plano incorporou outras cinco que responderiam a demandas postas pelo debate nacional.

No caso da Colômbia, apesar da dificuldade gerada pela organização, diversidade de categorias e extensão do documento, foi possível identificar que os temas-marco correspondem aos títulos dos segmentos em que se dividem os macro-objetivos.

\footnotetext{
16 A Constituição (1988) estabelecia no artigo 214: I - Erradicação do analfabetismo, II Universalização do atendimento escolar, III - Melhoria da qualidade de ensino, IV - Formação para o trabalho e, V - Promoção humanística, científica e tecnológica do País.
} 


\section{Quadro 1. Temas-marco.}

\begin{tabular}{|c|c|c|}
\hline & $\begin{array}{c}\text { PNE Brasil - Diretrizes } \\
\text { (BRASIL,Lei13.005/14, p.1) }\end{array}$ & PNDE Colômbia - Títulos dos segmentos \\
\hline I & Erradicação do analfabetismo & $\begin{array}{c}\text { Fins da educação e sua qualidade no século XXI. } \\
\text { (Globalização e autonomia) }\end{array}$ \\
\hline III & $\begin{array}{c}\text { Universalização do atendimento escolar } \\
\text { com ênfase na promoção da cidadania } \\
\text { e na erradicação de todas as formas de } \\
\text { discriminação. }\end{array}$ & $\begin{array}{c}\text { Educação em e para a paz, a convivência e a } \\
\text { cidadania. }\end{array}$ \\
\hline IV & Melhoria da qualidade da educação pedagógica e uso das TICs na \\
educação
\end{tabular}

A comparação inicial destes temas-marco permite destacar três aspectos importantes: i. A forma dos enunciados varia entre os documentos; ii. De maneira geral - com exceção do analfabetismo e da "universalização do atendimento escolar, no documento brasileiro, e do "Desenvolvimento infantil e educação inicial" e "Outros atores no (e para além do) sistema educativo", no documento colombiano - oito dos dez temas-marco do documento brasileiro apresentam seu correlato no plano colombiano, indicando tratar-se de temas importantes para ambos os países: iii. Além de temas que não têm equivalentes em cada documento, que se revelam de uma importância singular e diferenciada em cada país, quando dividimos os enunciados em frases, observamos que há temas que poderiam ter uma importância singular no contexto de cada país. 


\section{A FORMA DOS ENUNCIADOS}

Apesar da natureza contextual e do decorrente grau de generalidade de alguns dos temas, ao se comparar a redação dos enunciados são perceptíveis as diferenças entre os documentos em relação ao nível de abstração.

O documento brasileiro é mais concreto e claro em suas pretensões, o que se revela no fato de iniciar cada um dos temas-marco com uma ação como erradicar, universalizar, superar, melhorar, formar, promover, estabelecer e valorizar - ao mesmo tempo em que ratifica a clareza e o caráter prescritivo desse documento e implica numa perspectiva mais concreta de execução pelos entes governamentais.

Já os temas-marco do plano colombiano se dividem da seguinte forma: seis nomeiam ou descrevem (frases nominais) e quatro estipulam claramente uma ação (orações), como educar, renovar e usar, integrar e investir, o que faz com que, no intuito de ser abrangente, se fragilize seu caráter referencial.

\section{CORRELATOS E SUA RELAÇÃO COM A AGENDA MUNDIAL}

Como visto, oito dos dez temas-marco constam dos dois documentos numa correspondência entre temas que, mais do que aleatória, parece estar alinhada com uma agenda mundial que pode ser identificada em inúmeros documentos e reuniões internacionais, cuja preocupação principal é a educação escolar, inclusive nos países em desenvolvimento. Em revisão de políticas educacionais baseadas em documentos e reuniões internacionais da década de $1990^{17}$, Rodríguez (2002) identifica o compartilhamento das seguintes características: "A) a função prioritária da educação é a adequação dos indivíduos para responderem às mudanças econômicas e ao progresso científico e tecnológico; B) a determinação da qualidade e a equidade como eixos da política educativa; C) a primazia da análise econômica e dos economistas na tomada de decisões educacionais; D) a maior presença (financeira e técnica) dos organismos internacionais; E) a chegada de novos atores na elaboração e execução da política pública (principalmente: empresários, ONGs e os pais de família); F) a hierarquização dos agentes educativos; G) a definição da educação básica como prioritária; H) a priorização

\footnotetext{
17 No estudo que referimos (RODRÍGUEZ, 2002) são mencionadas 12 reuniões, declarações ou informes. As características principias - mencionadas pelo autor- são extraídas de cinco delas: a Conferência Mundial de Educação para Todos (Jontiem, 1990); a Cúpula Mundial pela infância (Nova york, 1990); o projeto principal de educação para América Latina e o Caribe, da OREAL-UNESCO (Quito, 1981); a a proposta educação e conhecimento; eixo da transformação produtiva com equidade, da CEPAL e a UNESCO (1992); a Declaração e Plano de Ação da - primeira e segunda - Cúpula das Américas (Miami, 1994; Santiago do Chile, 1997), Prioridades e Estratégias para a Educação, do Banco Mundial (1996).
}

184 - RBPAE - v. 32, n. 1, p. 171 - 192 jan./abr. 2016 
da descentralização e a autonomia escolar e, finalmente, I) a instauração e mecanismos de controle das instituições educacionais mediante a avaliação de resultados e accountability.(RODRÍGUEZ, 2002. Segundo o autor:

\begin{abstract}
No campo das estratégias recomendáveis para impulsionar as reformas, produzemse também mudanças importantes: considera-se a necessidade de substituir as políticas educativas de governo por políticas de Estado; conceber a reforma como massiva, integral e gradual, e fazer consultas e procurar acordos para a validação de políticas educativas. (Idem, p.106 - tradução nossa).
\end{abstract}

Mais recentemente, podemos localizar essa agenda nas diversas conferências e informes elaborados por organizações mundiais como a UNESCO, com as Conferências Internacionais de Educação da Oficina Internacional de Educação e o Posicionamento do Conselho Educativo sobre a Educação depois de 2015; como a ONU, com os Informes de Desenvolvimento Humano, produzidos anualmente desde 1990 pelo Programa das Nações Unidas para o Desenvolvimento (PNUD) e, como o BID, com seus diferentes projetos de cooperação técnica na área da educação.

$\mathrm{Na}$ Figura 1 podem-se observar os temas-marco dos documentos dos dois países e sua relação com parte das dimensões identificadas por Rodríguez e também com algumas características da agenda mundial para a educação. 
Figura 1. Correlatos dos planos e sua relação com a agenda mundial

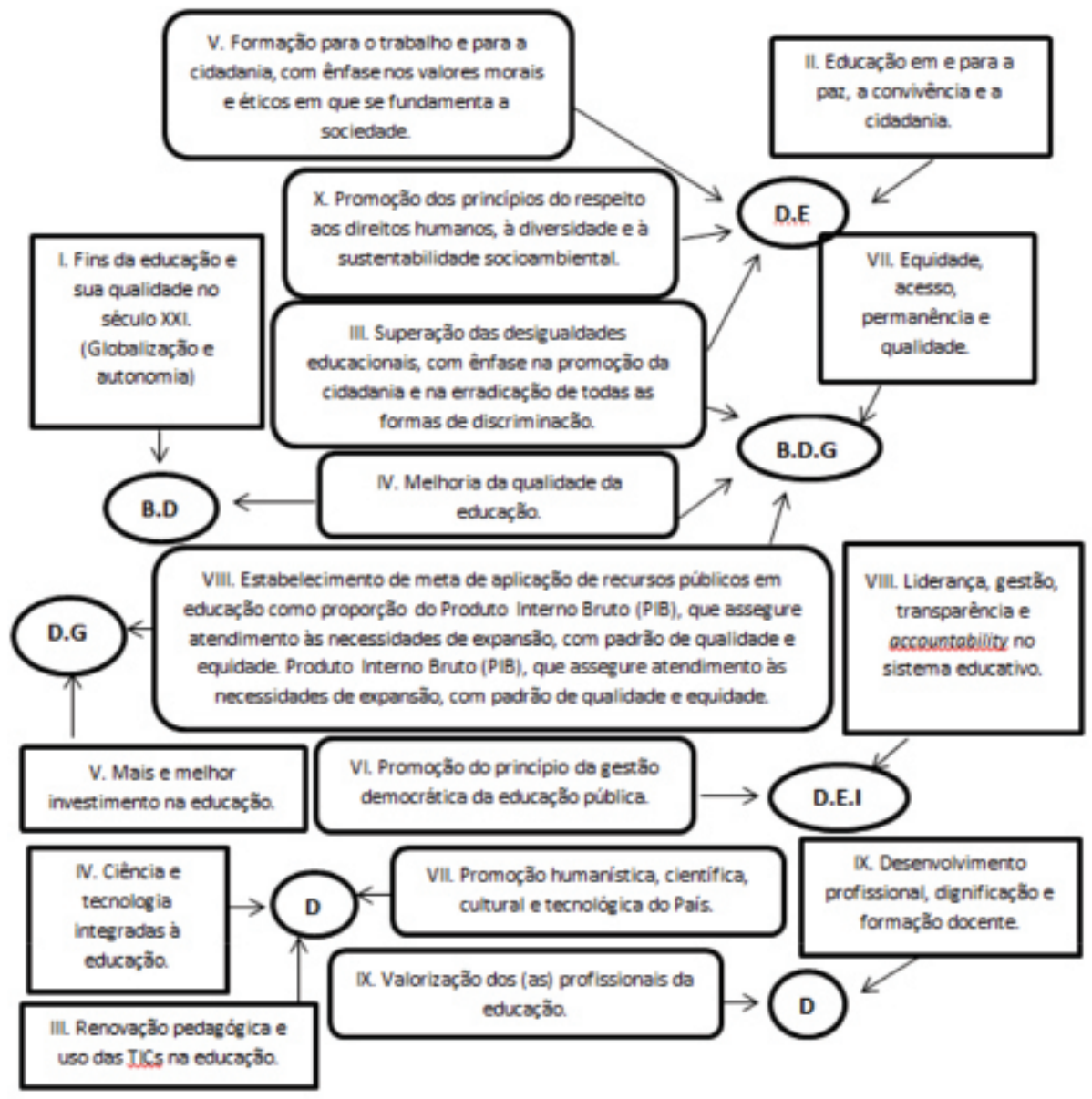

\section{LEGENDA}

PNE colombiano

PNE brasileiro

Carateristicas agenda mundial educação

\section{AS METAS DOS PNEs}

O que no plano brasileiro é uma meta, no plano colombiano é um macro-objetivo. São vinte as metas do documento brasileiro e cinquenta as do colombiano. Do ponto de vista formal, as metas do PNE brasileiro estão escritas no anexo da lei, depois dos caputs que regulamentam a difusão, execução e 
cumprimento do plano. As metas do plano colombiano estão divididas em seções de acordo com os temas-marco acima mencionados.

Uma primeira diferença decorrente da comparação das metas diz respeito à abrangência do âmbito de referência de cada plano. Enquanto o plano brasileiro está focado em metas apenas escolares para a educação básica e superior, o plano colombiano aborda a educação não apenas no âmbito formal do sistema educacional, como se observa, nos quatro últimos temas, que tratam de outros atores do processo educacional, como a família, o setor produtivo, os meios de comunicação e os espaços culturais.

A comparação dos temas de cada meta nos planos revela que ambos os países compartilham dificuldades e anseios educacionais que também guardam relação com o contexto regional e mundial, assim como em termos de respostas às agendas educacionais mundiais. Com exceção da Educação de Jovens e Adultos (EJA) e matrículas, todos os temas contemplados nas metas do plano brasileiro podem ser identificados no plano colombiano. Para ambos os países, a educação básica é uma prioridade e isto se revela no número maior de metas que guardam relação direita com essa etapa escolar. De outro lado, quando comparamos o número de metas existentes para cada tema, podemos observar que as TICs e o investimento se destacam no documento colombiano, ao passo em que o documento brasileiro enfatiza o Ensino Superior e a Valorização Docente.

Podemos observar, também, que as metas estipuladas no documento brasileiro possuem maior concretude que as do plano colombiano. No PNE vigente no Brasil, há um tema para cada meta e prazos estabelecidos para sua execução. Além disso, quando necessário, definem-se responsáveis e orçamentos. Por sua vez, no documento da Colômbia, cada meta possui dois ou três temas principais que, por vezes, aparecem articulados com temas que não pertencem necessariamente à educação e para os quais os prazos e os responsáveis quase nunca são estabelecidos. Isso faz com que suas metas sejam normas programáticas que têm aplicação diferida e mediata, além de implicarem a elaboração de outras regras capazes de torná-las exequíveis.

As primeiras metas estipuladas em cada um dos documentos ilustram esse ponto:

Universalizar, até 2016, a educação infantil na pré-escola para as crianças de 4 (quatro) a 5 (cinco) anos de idade e ampliar a oferta de educação infantil em creches de forma a atender, no mínimo, 50\% (cinquenta por cento) das crianças de até 3 (três) anos até o final da vigência deste PNE.(BRASIL, 2014, p.5)

Articulação e coerência do sistema educativo. Atingir um sistema educativo articulado, coerente e contextualizado nos diferentes níveis de formação e nas regiões; que possibilite a mobilidade e a formação integral da infância e juventude 
colombiana, num entorno democrático, pacífico e globalizado. (COLÔMBIA, PNDE, p.16 - tradução nossa).

Na meta brasileira, a educação infantil é o tema principal, estabelecendose prazos tanto para sua ampliação como para sua universalização e se indicando claramente os beneficiários. $\mathrm{Na}$ meta colombiana, existem dois temas principais: o sistema educativo e a formação integral da infância e da juventude, articulados com o tema de um entorno, democrático, pacifico e globalizado, que não depende exclusivamente da educação. Assim, quanto à definição do nível mais geral das metas, o PNE colombiano parece ser mais ambicioso e menos realista.

\section{CONCLUSÕES}

A comparação exploratória dos PNEs brasileiro e colombiano permite identificar semelhanças e diferenças entre os documentos tanto na sua origem, como no processo de elaboração e no resultado final. Nossa leitura se concentrou no que e no como foi dito, o que nos permitiu descobrir a riqueza da intenção normativa desses planejamentos educacionais.

Observamos que, tanto no Brasil como na Colômbia, esses planos educacionais têm origem política e social similar, produto das reformas constitucionais e das leis que delas derivaram, assim como de um esforço por garantir o exercício democrático da participação cidadã.

Já a comparação da natureza legal dos documentos permitiu apontar dois aspectos relevantes: 1) a potencialidade das leis como mecanismo de pressão cidadã, no caso brasileiro e, 2) a tensão entre a intensificação do caráter democrático da elaboração do documento e a falta de respaldo jurídico para que o documento seja efetivamente levado em conta, no caso colombiano.

Ao abordar os dissensos do documento colombiano, identificamos uma disputa pelos usos da língua e uma polarização ideológica. Já nos temas-marco dos documentos (Diretrizes, no caso brasileiro, Capítulos, no caso colombiano), identificamos uma maior exequibilidade e clareza em relação às ações esperadas no plano brasileiro.

Também observamos que a maioria dos temas está presente nos dois documentos, o que revela, em parte, sua relação com uma agenda mundial para a educação. Ao mesmo tempo, vimos também que alguns temas-marco possuem importância maior em cada país, o que, por outra parte, não deixa de representar uma resposta particular a demandas contextuais nacionais. Isso acontece, por exemplo, no caso dos temas-marco, que apresentam, em cada documento, algumas metas que respondem pelo contexto de cada país.

188 - RBPAE - v. 32, n. 1, p. 171 - 192 jan./abr. 2016 
Finalmente, na leitura dos documentos, identificamos que o plano brasileiro está focado no planejamento escolar, ao passo que o colombiano ultrapassa os muros da escola, apesar de os dois convergirem na prioridade dada à educação básica.

No concernente ao caráter exploratório do estudo, podemos afirmar que sua importância reside em mostrar a potencialidade do objeto de estudo para ser abordado a partir de diferentes intencionalidades e perspectivas. Em uma perspectiva sociológica, por exemplo, seria relevante avançar no estudo do papel dos agentes (indivíduos e instituições) na elaboração do documento e nas práticas dele derivadas, o que certamente destaca o potencial e a importância do estudo dos dissensos registrados no documento colombiano. E, ainda, em campos de saber interdisciplinares, como o da educação e o dos estudos culturais, a análise das relações de poder e dos discursos dos documentos poderiam contribuir para uma melhor compreensão da complexidade de temas como a formação docente, a avaliação e o caráter público da educação.

\section{REFERÊNCIAS}

BALL, Stephen. Sociologia das políticas educacionais e pesquisa críticosocial: uma revisão pessoal das políticas educacionais e da pesquisa em política educacional. Currículo sem Fronteiras, v. 6, n. 2, p. 10-32, Jul/Dez.2006.

BAUER, M. Análise de Conteúdo Clássica: uma revisão. In: BAUER, M.; GASKELL, G. Pesquisa qualitativa com texto, imagem e som: um manual prático. 2.ed. Petrópolis: Vozes, 2003, p.189-217.

BORDIGNON, G. (Colaborador Especial); QUEIROZ, A; GOMES, L. Plano Nacional de Educação: o planejamento educacional no Brasil. Junho/2011.

BRASIL. Constituição (1988). Constituição da República Federativa do Brasil. Brasília, DF: Senado, 1988.

BRASIL. Lei n. 9.394, de 20 de dezembro de 1996. Estabelece as diretrizes e bases da Educação Nacional. Brasília, DF, 23 dez. 1996.

BRASIL. Lei no 13.005, de 25/06/2014. Dispõe e aprova sobre o Plano Nacional de Educação - PNE e dá outras providências. DF, 25 dez. 2014. 
CAJIAO, Francisco. La concertación de la educación en Colombia. Revista Iberoamericana de Educación, no 34 (2004), pp. 31-47

COLÔMBIA. Constitución 1991. 1991Disponível em: http://www. banrepcultural.org/blaavirtual/derecho/constitucion-politica-de-colombia-.

COLÔMBIA. Ley 115 de Febrero 8 de 1994. MEN. 1994. Disponível em: http:/ /www.mineducacion.gov.co/normatividad/1753/w3-article-85906.html

COLÔMBIA. Ley 1151 de 2007. MEN. 2007. Disponível em: http://www. mineducacion.gov.co/normatividad/1753/articles-146170_archivo_pdf. unknown

COLÔMBIA. Ley 1450 de 16 de junio de 2011. MEN. 2011. Disponível em: https:// colaboracion.dnp.gov.co/CDT/Normatividad/ley145016062011.pdf

COLÔMBIA. Plan Nacional Decenal de Educación 2006 - 2016. Pacto social por la educación. Compendio General. MEN. Disponível em: http:/ /www. plandecenal.edu.co/html/1726/w3-article-166057.html

CURY, Carlos Roberto Jamil. Por um Sistema Nacional de Educação. São Paulo, SP. Editora Moderna, 2009.

FONSECA, Marília. Políticas Públicas para a Qualidade da Educação Brasileira: entre o utilitarismo econômico e a responsabilidade social. Cad. Cedes, Campinas vol. 29, n. 78, p. 153-177, maio/ago. 2009.

HERRERA, Martha; INFANTE, Raúl. Las políticas públicas y su impacto en el sistema educativo colombiano. Una mirada desde los planes de desarrollo 1970-2002. Nómadas, Colombia, Número 20, 2004, p.76-84. Universidad Central, Bogotá, Colombia.

MENDES, Durmeval Trigueiro. O planejamento Educacional no Brasil. Rio de Janeiro: EdUERJ, 2000.

RODRÍGUEZ, Abel: La educación después de la Constitución del 91, Bogotá, Magisterio., 2002. 
SAVIANI, Dermeval. Plano Nacional de Educação: antecedentes históricos. In: Da Nova LDB ao Novo Plano Nacional de Educação: Por Uma Outra Política Educacional. $5^{\text {a }}$ ed. Campinas, SP: Autores Associados, 2004.

SAVIANI, Dermeval. Sistema Nacional de Educação e Plano Nacional de Educação: significado, controvérsias e perspectivas. Campinas, SP: Autores Associados, 2014. - (Coleção Polêmicas do Nosso Tempo).

SILVA, Maria Juliana de Almeida e. A avaliação de Sistemas de Ensino no contexto da Regulação das Políticas Públicas. In: IV Simpósio Internacional o Estado e as Políticas Educacionais no tempo presente, 2008, Uberlândia- Minas Gerais. IV Simpósio Internacional o Estado e as Políticas Educacionais no Tempo Presente, 2008. Disponível em: http://www.simposioestadopoliticas.ufu. br/imagens/anais/pdf/DC02.pdf

VALENTE, Ivan; ROMANO, Roberto. PNE: Plano Nacional de Educação ou carta de intenção? Educ. Soc. Campinas, v. 23, n. 80, setembro/2002, p. $96-$ 107.

DIANA MARCELA CUERVO-ESCOBAR é doutoranda em Ciências Humanas - Educação pela Pontifícia Universidade Católica do Rio de Janeiro (PUCRio). Mestre em Estudos Culturais pela Universidad de los Andes, Colômbia. Pesquisadora do Laboratório de Avaliação da Educação LAEd. Tem experiência de ensino nas áreas de Linguística, Estudos Culturais e Educação; experiência de pesquisa nas áreas de Cidadania e Educação, e Política Educacional. E-mail: dicuerv@gmail.com

CINTIA DA COSTA é mestranda em Educação Brasileira (PUC-Rio). Especialista em Educação Especial (Unirio), Alfabetização (UFF) e Psicopedagogia (UERJ). Graduada em Pedagogia pela Universidade Federal Fluminense (UFF). Atua como Pedagoga na rede Municipal de Niterói e Orientadora Educacional na rede Municipal de Duque de Caxias. Endereço: Av. 22 de Novembro, 123 fundos c/1 Fonseca, Niterói RJ. CEP: 24.120-049. E-mail: cintianado@gmail.com; cintianado@bol.com.br

ALICIA MARIA CATALANO DE BONAMINO é doutora em Educação pela Pontifícia Universidade Católica do Rio de Janeiro. Professora associada da PUC-Rio e 
Pesquisadora do Laboratório de Avaliação da Educação -LAEd. Tem experiência de pesquisa e ensino na área de Política Educacional, atuando principalmente nos seguintes temas: avaliação da educação básica, aprendizagem nos anos iniciais do ensino fundamental e desigualdades educacionais. E-mail: aliciamcbonamino@ gmail.com

Recebido em fevereiro de 2016

Aprovado em abril de 2016 